Article

\title{
Sustainable Consumption Dilemmas
}

\author{
Kees Vringer ${ }^{1}$, Eline van der Heijden ${ }^{2}$, Daan van Soest ${ }^{2, *}$, Herman Vollebergh ${ }^{1,2}$ and \\ Frank Dietz ${ }^{1}$ \\ 1 Netherlands Environmental Assessment Agency (PBL), 2594 AV The Hague, The Netherlands; \\ Kees.Vringer@pbl.nl (K.V.); herman.vollebergh@pbl.nl (H.V.); frank.dietz@pbl.nl (F.D.) \\ 2 Tilburg Sustainability Centre and Department of Economics, Tilburg University, 5037 AB Tilburg, \\ The Netherlands; Eline.vanderheijden@uvt.nl \\ * Correspondence: d.p.vansoest@uvt.nl; Tel.: +31-13-466-2072
}

Academic Editor: Gerrit Antonides

Received: 30 January 2017; Accepted: 25 May 2017; Published: 3 June 2017

\begin{abstract}
To examine which considerations play a role when individuals make decisions to purchase sustainable product varieties or not, we have conducted a large scale field experiment with more than 600 participating households. Households can vote on whether the budgets they receive should only be spent on purchasing the sustainable product variety, or whether every household in a group is free to spend their budget on any product variety. By conducting several treatments, we tested whether people tend to view sustainable consumption as a social dilemma or as a moral dilemma. We find little support for the hypothesis that social dilemma considerations are the key drivers of sustainable consumption behaviour. Participants seem to be caught in a moral dilemma in which they not only weigh their individual financial costs with the sustainable benefits but they also consider the consequences of restricting other people's freedom of choice. Complementary survey results further substantiate this claim and show that many people are reluctant to impose restrictions on their peers, but, at the same time, our results also suggest substantial support for the government to regulate the availability of unsustainable product varieties.
\end{abstract}

Keywords: sustainable consumption; field experiment; social dilemma; moral dilemma

\section{Introduction}

Problems of sustainability and sustainable development tend to be more wicked: (i) the less consensus there is regarding the (perceived) urgency of the problem; and, not unrelated, (ii) the larger the distance (geographically, or temporally) between beneficiaries of sustainability actions and those who bear the costs of providing them. An example in point is climate change. Future generations, especially those living closest to the equator, will benefit most from climate change mitigation actions, while the costs of these actions need to be incurred by the current generations, and especially those living in the richer countries [1]. That means that considerations such as ethical stance, morality, warm glow and social identity are likely to play an important role in individual decisions whether to (voluntarily) contribute to solving these wicked sustainability problems [2-4]. However, more mundane explanations also exist. (In)action may also be the result of social dilemma considerations [5-7]. Each individual has a negligible impact on solving wicked sustainability problems, and the private costs of taking sustainability actions may be larger than the private returns received by the decision maker. Social dilemmas can be overcome by means of regulations (such as bans) or other inducements (such as subsidies or taxes) that either force all those affected to undertake sustainability actions, or change the cost-benefit ratio such that the sustainability actions become the cheaper actions. When offered the possibility to express one's opinion about the desirability of these regulations or inducements (for example in case of a binding referendum), an individual's support for the regulation 
would be an increasing function of the number of (other) individuals affected. The larger the number of individuals that can be committed to undertake the sustainable actions, the more likely it is that an individual will vote in favour of such inducements or regulations-because for the same amount of costs incurred by the individual, the impact of collective action will be higher the larger the number of individuals who are contributing too. This holds, for example, for decisions of households to consume the sustainable or conventional variety of a particular product.

In this paper, we explore which of the possible motivations or considerations are the most important drivers of sustainability behaviour-social dilemma considerations, or more personal considerations such as personal morality [8]. We do so by implementing a large scale (semi-)field experiment with more than 600 participating households, which were endowed with a budget that they could spend on either a sustainable or on a conventional product variety. The budgets offered varied with the size and composition of the household, and both product varieties were easily available in (local) shops and supermarkets. The typical procedure was that participating households voted on whether the available budgets had to be spent on purchasing sustainable product varieties or that every household was free to spend it on either product variety. Next, they were informed of the (majority) voting outcome, after which they could purchase the product variety in their preferred shop or supermarket. Finally, they were reimbursed for their purchases up to the amount of money available in their budget-if and only if their purchases were in line with the majority voting outcome.

The key treatments are those in which the voting outcome is binding; if the majority voted in favour of the rule that the available budgets could only be spent on the sustainable product variety, all households in the group are required to do so. Implementing this "binding referendum mechanism" (or "regulation") in groups of different sizes (1 household, 31 households or 61 households) provides a test of whether or not social dilemma considerations are an important driver of sustainable consumption decisions. Because of the public good characteristics of sustainable consumption, agents are expected to derive utility from the sustainability impacts of all sustainable consumption activities-their own, but also those done by the other households in their group. Note that this is fully analogous to the canonical public goods game-also known as the Voluntary Contribution Mechanism; see for example [9]. The amount of money spent on the sustainable product variety in our field experiment can be viewed as the amount of money contributed to the public account in a standard PG - because each individual household cares about the positive sustainability benefits of their group's total consumption, not just about their own. With smaller group sizes, a household may prefer to vote against the group being obliged to purchase the sustainable product variety because the extra costs of sustainable consumption they incur may be larger than the household's perceived welfare benefits obtained if the vote passes, and all households in their group (have to) purchase the sustainable product variety. If the majority voting outcome is in favour of the rule that all households should spend their budgets on purchasing the sustainable product variety, the positive impact is larger if there are 61 households in a group than if there are 31 or just 1 household in a group. For those agents who care about sustainability, the benefits of voting in favour of compulsory purchase of sustainable are larger the larger the size of the group. However, the costs agents face when purchasing the sustainable product variety is the same independent of the size of the group. After all, the price of the product varieties in the shop is fixed, and the extra costs associated with buying the sustainable product variety oneself is just equal to the price difference between the sustainable and the conventional product variety. With larger group size, the environmental benefits of voting in favour of sustainable product consumption are larger while the costs remain constant, and hence the share of votes in favour of sustainable consumption purchases is expected to increase in group size-if and only if social dilemma considerations are an important driver of voting decisions.

The specific product we use in this study is meat, where organic meat is considered the sustainable product variety. As stated before, problems of sustainability and sustainable development tend to be more wicked the less consensus there is regarding the (perceived) urgency of the problem, and -not unrelated — the larger the distance (geographically, or temporally) between beneficiaries of 
sustainability actions and those who bear the costs of providing them. Climate change is probably the most important sustainability challenge the planet currently faces, but the impact of individual behaviour on climate change outcomes is too small to be amenable for experimentation-and the same holds for other big sustainability issues, such as biodiversity conservation, deforestation and depletion of the high sea fisheries. Given that we want to test whether moral or social dilemma considerations are the most important driver of the (lack of) sustainable consumption behaviour, we needed to choose a consumption product: (i) that would not be too expensive; (ii) where both conventional and sustainable product varieties are readily available in the shops; and (iii) where a coordinated action of reasonably large groups of individuals (groups of 31 households) would result in a considerable improvement of the sustainability problem at hand.

In our search for a suitable product group, we decided to use meat for our experiment. Although there is some debate about the sustainability value of organic food products, we argue that organic meat can be considered to be a (more) sustainable product. The Sustainability Assessment of Food and Agriculture systems (SAFA) Guidelines-developed for assessing the impact of food and agriculture operations on the environment and people - state that food and agriculture systems worldwide can (and should) be evaluated on all four dimensions of sustainability: good governance, environmental integrity, economic resilience and social well-being ([10], p. 2, see also [11]). While little is known about the differential performance on governance criteria, organic meat production tends to outperform conventional meat production on two criteria. Regarding economic resilience organic farming seems to have advantages compared with conventional farming, as it is less reliant on external inputs and has a stronger ability to conserve natural resources [12]. Social well-being includes criteria such as good quality life, animal welfare and the impacts on the welfare of future generation, and organic farming practices score better on these criteria too [13]—and then especially so on animal welfare [14].

Based on a meta-analysis of studies comparing the environmental impacts of organic and conventional meat production in Northern Europe, [15] conclude it is not possible to draw a conclusive picture on the general environmental performance of the different farming systems. While it is difficult to determine with certainty whether the positive sustainability impacts of organic (as compared to conventional) meat production outweigh the negative ones, organic meat production brings clearly more animal welfare than conventional meat production. Taken together, organic meat production tends to be more sustainable than conventional meat production, but, of course, a vegetarian or a vegan life style is likely to be even more sustainable.

Pre-testing revealed that the sustainability consequences of organic meat consumption by a concerted action of 31 households-and then especially the improvements in animal welfare that organic meat production gives rise to, resulting in about 40 chickens having had a better life, as compared to the consumption of conventional meat-was perceived as a sizable impact. In addition, among non-vegetarians, organic meat is perceived as more sustainable than conventional meat, and it is a wicked problem in the sense that the weights people attach to animal welfare differs considerably too. Organic versus conventional meat consumption was thus chosen as the sustainable versus standard product variety. In addition, note that for those households that care about animal welfare, organic meat consumption is a public good. These households value the positive sustainability benefits of their group's total consumption (theirs and those of all other households purchasing organic meat), not just about their own. After all, there is neither rivalry in consumption of the sustainability consequences of purchasing organic meat-the improvement in animal welfare-nor can non-contributors be excluded from enjoying those benefits. As such, the animal welfare consequences of organic meat consumption are a public good. Thus, organic meat has all the necessary characteristics of a social-dilemma consumption good.

Previewing our results, we find only little support for the hypothesis that social dilemma considerations are the key factor driving (the lack of) sustainable consumption behaviour. The share of households voting in favour of the regulation is not an increasing function of the size of the group. Moreover, we do not find substantial differences in shares of households voting in favour of 
the regulation if it is binding or if it is non-binding. When households have the option to commit themselves conditionally to the share of households that are also willing to do so, we find that the propensity for voluntary commitment does not strongly increase with group size. Interestingly, we do find that the propensity to vote in favour of the regulation is significantly higher if it is framed as a less-restrictive measure-that is, in the form of a subsidy rather than as a ban. We thus do not find substantial experimental evidence that social dilemma considerations are the main drivers of (the lack of) sustainable consumption behaviour, and we offer complementary survey results to further substantiate this claim.

We are not the first to try to identify the key drivers of (in)action in sustainability problems (see for example [16-20]). Previous studies have focused on identifying the relevance of various motivations hampering or fostering sustainable consumption decisions. For example, Moisander [19] and Kurz [21] analyse the role of motivational complexity, and Gupta and Ogden [22] concentrate on the social dilemma aspects of the problem. Rather than using standard survey methods (e.g., [23,24]), we implement a large-scale financially-incentivized field experiment regarding consumption decisions that households make on a daily basis. Furthermore, our participants are a representative sample of the population of Dutch non-vegetarian households, and they make their purchase decisions in the environment where typically these types of decisions are taken-in their homes, and in the supermarket.

The remainder of the paper is organized as follows. In Section 2, we present the theoretical background as well as the experimental design, and in Section 3 we present the results. Section 4 concludes.

\section{Theoretical Background and Experimental Design}

\subsection{Social versus Moral Dilemmas}

In the European Union, the share of consumers buying sustainable product varieties is typically quite low [25]. This also applies to the Netherlands, the country in which this study was implemented. The market share of sustainable products in the Netherlands usually does not exceed 5-10\% [26-28], yet surveys consistently show that Dutch consumers consider sustainability one of the most pressing societal issues (e.g., [29,30]). Apparently, most Dutch consumers are not willing or able to voluntarily change their consumption patterns to increase sustainability.

To consider sustainability important without acting upon this belief is consistent with a social dilemma. A social dilemma arises if two conditions are met (for classic contributions on the role of social dilemmas in daily life, see for example Olson [5] and Schelling [31], and for an early theoretical analysis, see Sen [32]): (i) collective welfare is maximized if all members of the community undertake a specific action; and (ii) individual members can maximize their private welfare by not undertaking this specific action, but this will be at the expense of collective welfare. Indeed, the individual costs of buying sustainable product varieties are relatively high (with price premiums for such products amounting to $10-50 \%$ compared to conventional varieties), but society is best off if everyone makes this individual contribution. However, individuals are better off free-riding on the investments made by others, than making investments in the collective good (sustainability) themselves. From this reasoning, it is not surprising that consumers support the idea of more far-reaching government measures to promote sustainable consumption—such measures would help to resolve the dilemma. In 2007 , as many as $70 \%$ of Dutch citizens subscribed the proposition that the government should take the initiative in solving important societal issues [33]. A recent example for this is the strong support of the Dutch population for stricter building regulations to improve their energy efficiency [34].

However, the oftentimes fierce public debates about concrete measures suggest that also something else could be at play. Perhaps it is too easy for survey respondents to say that they consider sustainability important and that government measures are needed, and that this is the case not just in standard surveys (which pose questions on the respondent's opinion, attitudes and behaviours) but also in stated-preference valuation techniques such as contingent valuation and discrete choice 
experiments. Due to the hypothetical nature of surveys, these studies may overlook the possibility that consumers find sustainable products simply too expensive. Indeed, most studies on preferences related to nonmarket environmental goods employ contingent valuation (CV) and discrete choice experiments (also known as conjoint analysis) techniques [35]. While the literature often assumes that it in the respondents' own interest to truthfully answer a yes/no preference question ("Are you willing to pay $X$ euros for this project, yes or no?"), it appears that these survey techniques generally lead to an overestimation of the true willingness to pay. In the economic literature, this phenomenon is known as hypothetical bias, and in the social-psychological literature addressed as socially desirable answers. A good overview of the nature and degree of hypothetical bias is provided by the meta-analyses of [36,37], and by the literature reviews of Harrison [38], and Harrison and Rutström [39]. This bias arises because of "yea saying" (stating support for the socially desired project) or because of strategic considerations (when respondents say "yes" to a specific price even though they would not actually be willing to pay that price, just because the project is more likely to be implemented if they answer "yes" rather than "no"). Strategically or socially misrepresenting one's preferences is cheap because the respondent knows that her answers will not have direct financial consequences, as the payment question itself is hypothetical. Clearly, the potential for such hypothetical bias is particularly important for the present research in which we aim to explain the difference between consumers' (stated) support for policies promoting sustainable products, and their much less frequent purchase of such products. An additional or alternative explanation for this observed difference may be that people perceive sustainable consumption as a moral issue, so they take moral motives into consideration. When an individual is purchasing (food) products, he can be motivated by moral concerns as a citizen but also, and at the same time, care about product characteristics as a consumer $[40,41]$. The phenomenon that individuals' preferences and concerns do not always translate into purchase behaviour may be due to the dual entities that individuals may have, the so-called consumer-citizen duality, or discrepancy. Note that moral concerns may also include (restricting) freedom of choice of others.

\subsection{A Field Experiment}

To gain insight into whether sustainability issues are viewed as a social or a moral dilemma, we used both standard survey questions as well as an economic semi-field experiment (according to the classification by Harrison and List [42], our study is not a natural field experiment as participants were aware of the fact that they took part in a research project). A key characteristic of economic experiments is that decisions have real consequences-financial, or non-financial-for the decision maker herself, but maybe also for others. The participants in our experiment were a representative sample of Dutch consumers responsible for the food shopping in their household. Their households were provided with a budget (or "credit") that they could spend on either the sustainable or the conventional variety of specific product group, and hence decisions had real (financial and sustainability) consequences rather than that decisions were just hypothetical. Compared to standard laboratory experiments (using students as subjects), an important and unique feature of our study is that participants made their decisions in the environment where household decision making with respect to groceries typically takes place-at home, and/or in the supermarket. This way, participants were confronted with the real, tangible consequences of their personal beliefs (and those of others) about abstract values such as "sustainability" — and hence participants are expected to be better able to picture the consequences of their beliefs and actions on abstract values such as sustainability [43]. In addition, we believe that a distinctive and noteworthy aspect of our study is the large sample size: more than 600 household representatives participated in our experiment.

The experiment consisted of a number of stages; the general setup is displayed in Table 1. Before conducting the experiment in its definitive form, we tested the design in qualitative and quantitative pilot studies. Based on the results of these pilot studies, the original design was further optimized [44]. The aim of the qualitative pilot study was to check whether the information provided to the participants on conventional versus sustainable varieties of the product was clear and correctly 
understood. The quantitative pilot study was done to detect and solve any problems in the design before conducting the final experiment. After having carefully pretested the experimental design, we are confident that participants fully understood the instructions such that confusion can be ruled out as a factor driving our results. All information exchange took place through the Internet, and there was no contact between participants. In Phase 0 , we cooperated with an online survey company (TNS-NIPO) to recruit households from their database that would be a representative sample of (non-vegetarian) households in the Netherlands. Our subject pool is a representative sample of the population of non-vegetarian households in the Netherlands because: (i) we started with a representative sample of Dutch households; (ii) we mentioned neither the topic nor the purpose of our study in our contacts with the respondents in the selection phase of the study; and (iii) $93 \%$ of the households who were invited for the initial survey, ended up participating in the experiment. For a general analysis of meat consumption in the Netherlands, see Gilsing et al. [45] and also Dagevos and Voordouw [46]. Respondents were asked whether they were willing to participate in a study, and, if so, whether they were available during the entire period in which the study was implemented, whether they ate meat, and who was responsible for the household's groceries shopping. We also collected data such as disposable income, age, household composition and educational level.

Table 1. Overview of the timing of the experiment (2010).

\begin{tabular}{llll}
\hline Phase & \multicolumn{1}{c}{ Time } & \multicolumn{1}{c}{ Name } & \multicolumn{1}{c}{ Activities } \\
\hline 0 & $\begin{array}{l}\text { 27 August- } \\
\text { 12 September }\end{array}$ & Sample selection & Households were contacted and a sample was selected \\
\hline 1 & $\begin{array}{l}\text { 20 September- } \\
\text { 29 September }\end{array}$ & Experiment: Voting & $\begin{array}{l}\text { Households received instructions, voted on the proposition, and answered } \\
\text { some questions about motivation and expectations }\end{array}$ \\
\hline 2 & $\begin{array}{l}\text { 29 September- } \\
\text { 8 October }\end{array}$ & Purchases & $\begin{array}{l}\text { Households were informed about the voting outcome and could spend } \\
\text { their credit on (conventional and /or organic) meat }\end{array}$ \\
\hline $\begin{array}{l}\text { 8 October- } \\
\text { 17 October }\end{array}$ & Survey questions & $\begin{array}{l}\text { Households answered questions about how they felt about the voting } \\
\text { outcome, motivation to spend their money, some background questions. }\end{array}$ \\
\hline 4 & $\begin{array}{l}\text { 8 October- } \\
\text { 28 October }\end{array}$ & Reimbursement & $\begin{array}{l}\text { Participants were reimbursed dependent on whether they complied with } \\
\text { the group decision, verified using their receipts }\end{array}$ \\
\hline
\end{tabular}

The actual experiment took place in Phase 1, when participants had to decide whether or not to (jointly) address a sustainability problem. They were randomly divided into groups, and each participant was allocated an experimental budget (credit) to be spent on a product of which both a (less expensive) conventional and a (more expensive) sustainable variety were available in the supermarket. To minimize the potential impact of physical differences, the conventional and sustainable product varieties had to be as similar as possible. Furthermore, both varieties had to be widely available and known by most people. The product that we selected for our experiment, meat, meets these criteria. The physical properties such as quality and taste are more or less similar between conventional and organic meat [47-49], and both varieties are widely available and known to most people. However, organic meat is on average about twice as expensive as non-organic meat. If objectively conventional meat and organic meat are very similar in all other respects, this does not mean that people also perceive them as very similar. This holds for the meat's taste, its health consequences, and environmental impact (land use, energy intensity); see for example Gilsing et al. [45]. Note that including or omitting this information is likely to affect the levels of support for regulations, but not the treatment differences. Similarly, although we cannot rule out the possibility that social desirability "pressure" may have affected the level of support, there is no reason to believe that the perceived social desirability pressure varies between treatments, such that treatment differences are unaffected. Households in a group vote as to whether the budgets they all received can only be spent on purchasing the sustainable product variety, organic meat, or whether every household is free to spend their budget on either organic or conventional meat (see Section 2.3 for details). The budget (credit) received was based on the size and composition of their household—seven euros for every adult in the household, and four euros for every child-and was sufficient to cover the additional costs of buying organic meat for one week. 
After the voting (still in Phase 1), we asked the participants a number of questions related to voting motives and their expectations regarding the voting behaviour of other people.

In Phase 2, participants were informed about the outcome of the votes in their group, and the implications for their household, in particular about which type of meat would be reimbursed. Afterwards households had one week to spend their budget on actual meat purchase(s).

After the purchases, period Phase 3 started in which we asked participants whether they were happy with the voting outcome in their group, and why they spent the money in a particular way. We also asked them to what extent they thought that the government should take stricter measures to promote sustainable production and consumption, and some other background questions.

Finally, in Phase 4, households submitted the receipts of their meat purchases. After verifying that their behaviour was in line with the group decision, their costs were reimbursed (up the maximum credit available for their household).

\subsection{Treatments}

In the experiment, households were randomly allocated to six different treatments, which differed in either the rules dictating whether the budgets should be used to buy products of the sustainable variety, or in the number of households involved in the decision making process. Table 2 shows all the treatments as well as the number of participating households in each treatment. Each household participates in only one treatment (a between-subject design). Furthermore, all treatment differences are restricted to Phase 1 , such that the procedures, information provided in all phases, etc. are the same across all treatments. Even though people may have different perceptions about potential differences between conventional and organic meat (see discussion in Section 2.2), which may affect the share of participants buying organic meat in our six treatments, this should not affect any treatment differences. We rely on randomization combined with sufficiently large numbers of participants in each treatment in order to control for the unobserved characteristics across groups.

Table 2. Overview of the treatments.

\begin{tabular}{lccc}
\hline Treatment & Group Size & Binding? & Number of Participating Households ** \\
\hline 1. Ban, binding & 1 & Yes & 83 \\
2. Ban, binding * & 31 & Yes & 160 \\
3. Ban, binding & 61 & Yes & 111 \\
4. Ban, non-binding & 31 & No & 160 \\
5. Subsidy, binding & 31 & Yes & 83 \\
6. Conditional choice, binding & 31 & Yes & 721 \\
\hline Total number of participating households & & \\
* This is the main "binding ban" treatment described in Appendix A. ** Note that, in most treatments, the number \\
of participants is not a round multiple of group size. This is due to non-response. To determine the voting outcome \\
in incomplete groups, we randomly assigned participants from intact groups to incomplete groups to cover the \\
missing votes.
\end{tabular}

We manipulate details of the experimental decision-making environment in four ways. (i) To examine if social dilemma considerations play a role, we vary the group size (from 1 via 31 to 61 households in a group). If social dilemma considerations are the most important factor driving behaviour, we expect the share of households voting in favour of the regulation to increase in the size of the group. In addition, we also explore (ii) whether voting outcomes differ if the voting outcomes are non-binding rather than binding; (iii) if it matters whether the decision problem is framed less restrictively (as a subsidy rather than as a binding regulation); and (iv) how people vote if households can conditionally commit themselves to a particular outcome, depending on the share of households willing to do the same. We will describe the main treatment in most detail, and focus on the difference between this treatment and the other ones when describing the other five treatments. The usage of a between-subjects design brings along the risk of responses being insensitive to variations in "the size of the public good" offered, as is well-documented in the stated preference 
valuation literature. Reasons why respondents' valuations of a specific project (or policy) may not vary much with the amount of environmental benefits created include, among others, warm glow considerations and the embedding effect [50,51]. However, using a within-subjects design (rather than between-subjects) may also result in biased outcomes because of, among other factors, anchoring and mental accounting bias [52,53]. We are confident that if we find a lack of responsiveness of voting outcomes to, for example, variations in group sizes, this is not due to above the biases for two reasons. First, the information offered regarding group size is salient in our experiment because decisions have real (financial as well as animal welfare) consequences as opposed to hypothetical decision making in stated-preferences studies [54,55]. Second, as stated before, our pre-tests indicated that the difference in sustainability outcomes (including animal welfare consequences) was perceived to be substantial for the different group sizes.

The main treatment, on which all other treatments were based, was the .so-called "binding ban" treatment. In this treatment, a group of a specific size, 31 participants in the basic variant, had to decide, by majority vote, whether to prohibit using the budget for purchasing the conventional variety of the product. The group's decision (voting outcome) was binding. The participants were informed that if the average participating household in their group would decide to spend their budget on buying organic meat for one week, about one chicken would have a better life. However, if the group of 31 participating households decided to vote in favour, the extra costs per household of buying organic meat would be unchanged, while about 40 chickens would have a better life. The instructions also included information about the price difference between the conventional and sustainable variety of the product. The participants were asked to vote as to whether all members of the group should be obliged to use their (experimental) budget only for buying the sustainable alternative, or whether everyone should be free to spend it on the variety of their choice. The question was phrased as follows. The question posed was very similar in all treatments, but the exact formulation was adapted to details of the treatment (e.g., all 61 households when group size was 61). Note that we have not included words such as "prohibit" and "ban" in the experiment.

You are now asked to vote on the following proposition:

"All 31 households shall use their credit only for buying organic meat."

I vote IN FAVOUR (I think that all 31 households in my group should be obliged to use their credit only for buying organic meat).

$\square \quad$ I vote AGAINST (I think that all 31 households in my group should be free to use their credit for buying organic or non-organic meat).

The vote was binding, and hence the weakly dominant optimal strategy for a participant is to vote truthfully and according to their (household) preferences [35,56]. After the vote, all participants were informed about the voting outcome in their group (Phase 2). If the majority of the group had voted in favour, then the credit could indeed only be used for buying organic meat. Hence, the purchases of meat during the week following the vote were reimbursed only if they complied with the majority decision.

The first treatment variation in the experimental design is the group size. We implemented the binding ban treatment with not just group sizes of 31 participating households, but also with 1 and 61 participants in a group (Treatments 1 and 3 in Table 2). In these treatments, the text in the above-mentioned questions is adjusted as well as the information provided to the participants. In particular, we informed our participants in groups of one (61) household what the "animal welfare" consequences were of their whole group spending their budgets on organic as opposed to conventional meat: about one (80) chicken(s) would have a better life.

A second change involves the type of commitment (binding or advisory). In one treatment, the 31 participants in a group were asked the same question as to whether budgets should be spent on organic meat or not, but where the vote was only advisory (the non-binding ban, Treatment 4 in Table 2). Thus, here, when voting, participants knew that the group decision was not-binding: all meat purchases would be reimbursed, regardless of the type of meat and the voting outcome. 
Furthermore, we implemented a binding treatment in which the choice and consequences were similar to those in the binding ban treatment, but in which the situation was framed differently. In this so-called binding subsidy treatment (Treatment 5 in Table 2) the 31 participants of a group could vote as to whether all budgets should be used to subsidize the purchase of organic meat only of those who were willing to buy this type of meat rather than voting for or against a ban. If the group majority voted yes in the subsidy treatment, the price difference between the organic and the conventional variety was reimbursed. As in the binding ban treatment, the group decision was binding.

Finally, we also implemented a treatment in which we used the so-called strategy method [57] to ask participants as to whether they were willing to commit themselves to buying organic meat conditional on the number of other participants who were willing to do the same (the binding conditional choice treatment, Treatment 6 in Table 2). Here the participants were asked to indicate for six different situations what their decisions were (see Table 4). For example, one question was: "Are you willing to commit yourself to buying organic meat if 9-5 group members will also commit?" As in the main treatment, the outcome was binding.

Before presenting the results, we derive some predictions for expected differences between treatments. The treatments differed as to how (or by whom) it was decided where the budget could be spent on (the sustainable product variety, or the conventional one), but the rules regarding whether or not the credit was disbursed were always the same. If the outcome of the decision process in their group was that no households should spend their budget on the conventional product variety, they were reimbursed for the purchases of organic meat they made in the week in which the experiment took place. If the outcome of the decision process was that no regulations were to be imposed, all meat purchases (up to the allocated budget) were reimbursed independent of whether they purchased organic meat, or not. As organic meat is about twice as expensive as the conventional product variety and the budget per household was large enough for it to cover the extra costs of purchasing one week's supply of organic meat, the budget was sufficient to cover the costs of one week of conventional meat or half a week organic meat.

Obviously, the binding ban treatment with just one participant is essentially an individual commitment treatment, where the participant decides to commit her household to buying organic meat, or not. If participants view buying organic meat as a social dilemma, the share of participants voting in favour of the ban should be increasing in group size with 1,31 or 61 households (Prediction 1). After all, the extra costs of buying organic meat are unchanged but the environmental and/or social consequences of the ban are greater if the ban applies to more households. Similar considerations apply to the binding conditional treatment. Earlier experimental research has documented that a substantial fraction of people are conditional co-operators. For example, Fischbacher et al. [58] report that in a public good experiment half of the people are willing to contribute more to a public good the more others contribute. In our binding conditional treatment, the vote is also a voluntary contribution decision, and if participants are conditional co-operators and view sustainability as a social dilemma, the share of participants willing to commit themselves to purchasing the sustainable product variety can be expected to increase in the share of participants willing to commit themselves (Prediction 2).

Regarding the comparison between the binding ban and non-binding ban treatments one would expect higher shares of people in favour of the proposition when the ban is not binding (Prediction 3 ). One reason is hypothetical bias-people's tendency to signal their pro-sociality (yea-saying) if the outcome of a poll or question does not have any real consequences. Here one could always express one's support for organic meat consumption in the referendum while deciding to buy conventional meat in the supermarket instead. Another reason is that people may view the non-binding vote as an opportunity to influence other people's opinions and behaviour-expressing their support for organic meat in the referendum in the hope that it will induce other households to (also) buy organic meat.

A final comparison is between the binding ban and the subsidy treatment. These treatments are very similar, but the framing is slightly different. In the subsidy treatment households can vote whether the budget should be used to cover the extra costs of purchasing the sustainable product variety 
whereas in the main treatment they vote whether households should use their credit only for buying organic meat. From a cost-benefit analysis, voting in favour of the subsidy is (weakly) less attractive than voting in favour of the ban and hence, for given sustainability preferences, the participants are expected to be (weakly) less prone to voting in favour of the subsidy than to voting in favour of a ban (Prediction 4). The reason why voting in favour of the subsidy is weakly less attractive than voting for the ban is as follows. In the ban treatment, subjects receive compensation for their purchases of organic meat up to the maximum of the budget reserved for them. If they purchase the same amount of organic meat as they would normally do, they pay half of the bill themselves. In this case, the subsidy treatment and the binding ban treatment are identical. However, in the ban treatment, subjects can, in principle, just buy half of the normal quantity they typically consume per week, claim the entire budget, and buy additional meat of the conventional type. In that situation, voting in favour of the "policy" would be less costly to the participant in the binding ban treatment compared to the binding subsidy treatment since in the latter subjects would only receive half of the budget. The experimental results, however, indicate that this "strategy of just spending part of one's budget on organic meat" (rather than 0 , or all) is hardly ever used in the binding ban treatment.

\section{Results}

The results of the most important treatments are shown in Table 3 (for a complete overview of all treatments and results, see [44]), where the top panel presents results for the three binding ban treatments with different group sizes, and the bottom panel displays the results of all treatments with group size 31. We first present some general observations, and next discuss the most important findings in more detail in several subsections, including statistical tests to establish the significance of observed differences.

Table 3. Share of votes in favour of buying organic meat.

\begin{tabular}{lc}
\hline \multicolumn{2}{c}{ Share of Votes in Favour of Buying Organic Meat for Different Group Sizes } \\
\hline Treatment & Share in Favour of Buying Sustainable Variety \\
\hline 1. Binding ban, group size $1(\mathrm{~N}=83)$ & 0.51 \\
2. Binding ban, group size $31(\mathrm{~N}=160)$ & 0.42 \\
3. Binding ban, group size $61(\mathrm{~N}=111)$ & 0.50 \\
\hline \multicolumn{2}{c}{ Share of Votes in Favour of Buying } \\
\hline
\end{tabular}

The first observation is that the shares of votes in favour of (regulation of) the sustainable variety are remarkably high across all 6 treatments, considering the small market shares of organic meat in the Netherlands (3\%; [26]). The second observation from the top panel of Table 3 is that these shares barely vary with group size (Compare 1,2 and 3). Thirdly, comparing 2 and 4, we do not find a significant difference in the voting shares if the referendum outcome is binding, or not. If the vote is "advisory" only, $50 \%$ of the participants vote in favour, which is not much higher than the share of Yes votes in the binding ban treatment with 31 participants (42\%). Fourthly, comparing 2 and 5, the percentage of voters in favour of a "subsidy" on organic meat (57\%; Group Size 31 ) is found to be substantially higher than the percentage of voters in favour of a "ban" on buying non-organic meat (42\%; Group Size 31). This suggests that people prefer a subsidy over a ban, even though the "subsidy" was financially less attractive. Finally, by far the highest number of voters in favour of a binding ban can be observed in the "binding conditional choice" treatment (see 6 in the top panel of Table 3). As many as $76 \%$ of the 
participants in this treatment were willing to commit to buying organic meat, if a minimum number of other group members would do the same (more details are provided later, in Table 4). The larger the minimum number, the higher the percentage of participants willing to commit. Finally, virtually all participants spend their budgets in line with the voting outcome, and this is irrespective of the treatments. In the next subsections, we discuss these results in more detail.

\subsection{Consumers Willing to Buy Sustainable Products, But Up to Some Limit}

In our experiment the revealed willingness to commit oneself is considerable higher than what one observes in the real world (see Table 3). Interestingly, this percentage does not differ significantly between treatments with self-commitment (when group size is 1 ) and those where one could break through the social dilemma by committing others as well (in the treatments with groups of 31 or 61 participants). The same holds for the treatment where individuals were not committed to the group choice (non-binding ban). In the experiment consumers reveal a stronger (conditional or unconditional) willingness to buy more sustainable products than they do in the market place. If we combine our experimental results with self-reported organic meat consumption of participants, the support for the binding ban is not related to the purchase of sustainable product varieties in everyday life. In our experimental environment both groups vote "yes" about equally often. Indeed, over 50\% of participants who said to have never bought organic meat before still voted in favour of obliging themselves and others to spend their credit only on organic meat.

To check the influence of some other aspects on voting behaviour we checked the relation between voting behaviour on the one hand and gender, household size, income, age, education level and location on the other. Participants aged 70 or older are less likely to vote in favour of organic meat than younger age groups ( $30 \%$ vs. $45 \%$ for participants aged between 30 and $40 ; p=0.04$ ). Similarly, less educated participants are less likely to vote in favour of organic meat than higher educated participants ( $36 \%$ vs. $45 \%, p=0.032$ ), and participants from the big urban areas are less likely to vote in favour than the other participants ( $33 \%$ vs. $40 \%, p=0.048$ ). We did not find any significant differences in voting behaviour for income, gender and house size.

\subsection{Peer Pressure May Increase Support}

To investigate the role of the social dilemma more explicitly, we look at the effect of varying group size. As stated in Prediction 1, if participants view organic meat consumption as a social dilemma one would expect the percentage of Yes voters to increase with group size. As can be observed in Table 3, however, the shares of participants voting in favour of a binding ban are unrelated to group size, and all differences between the three treatments are statistically insignificant: comparing the shares in the standard groups of 31 (i.e., $42 \%$ ) to those with group sizes $1(51 \%)$ and $61(50 \%)$, the relevant $\chi^{2}$-tests yield insignificant $p$-values of 0.20 and 0.16 , respectively (the difference between $51 \%$ and $50 \%$, comparing groups of 1 and 61 , is also not significant $(p=0.98)$ ). These findings suggest that participants do not seem to weigh the size of the potential collective gains against their individual costs even though they were explicitly informed about the potential size of these collective gains before the vote, which is in contrast to Prediction 1.

Table 4. Percentage of participants willing to commit to buying organic meat, in the conditional choice treatment.

\begin{tabular}{lc}
\hline \multicolumn{1}{c}{ Condition } & \% of Yes Voters \\
\hline (1) All other group members will also commit $(100 \%)$ & 57 \\
(2) 22-29 group members will also commit $(71-94 \%)$ & 58 \\
(3) 16-21 group members will also commit (52-68\%) & 54 \\
(4) 9-15 group members will also commit (29-48\%) & 42 \\
(5) 1-8 group members will also commit (3-26\%) & 39 \\
(6) No other group members will commit (0\%) & 43 \\
Percentage of participants who voted Yes, under & 76 \\
at least one of the conditions (1-6) above & \\
\hline
\end{tabular}


While in this experiment the actual size of collective gains barely seems to matter, expectations with respect to the behaviour of others do seem to play a role. Whether people are willing to commit themselves turns out to be a function of other people's willingness to commit, apart from being actual or expected willingness. To substantiate this outcome one has to compare the percentages of Yes voters in the main (unconditional) binding ban treatment with the conditional choice treatment where group size is similar (31). In the unconditional treatment, $42 \%$ of the participants vote in favour of the binding agreement, which is virtually identical to the $43 \%$ of the participants in the conditional choice treatment reporting that they will commit to buying organic meat even if no other group member would commit (compare Tables 3 and 4). This percentage of $43 \%$ is also not significantly different from the $51 \%$ of Yes votes in the binding ban treatment with group size 1 ( $\chi^{2}$ test gives $p=0.53$ ). However, participants were more willing to commit to buying organic meat if they were sure that at least some other members of their group would do the same. Table 4 shows the larger the number of others willing to commit, the higher the percentage of participants willing to commit as well. Statistically, the percentage of Yes voters is significantly higher if more than half of the other group members would also commit (Conditions 1-3; see Table 4), than if less than half would also commit (Conditions 4 and 5), or than if nobody would commit (Condition 6), This finding is consistent with Prediction 2. (McNemar tests, comparing Conditions 1-3 with 4 and 5: $p=0.002-0.008$. $p$-values for the differences between Conditions 1 versus 6, 2 versus 6, and 3 versus 6) are 0.054, 0.038 and 0.093, respectively.) Finally, no less than $76 \%$ of the participants in the conditional choice treatment were willing to commit themselves in at least one of the six conditions, a percentage that is significantly larger than in the binding ban treatment $\left(p<0.01, \chi^{2}\right.$-test).

Conditionality may have also played a role in the decisions of participants in the non-conditional binding ban treatments. Indeed, Figure 1 shows a positive correlation between participants' own votes and their expectations regarding voting behaviour of the other group members: participants who expected more other members of their group to vote in favour of the binding agreement, also voted more in favour themselves, and thus were more willing to commit themselves as well as the other 30 or 60 members of their group to buying only organic meat. In addition, in the individual commitment treatment (i.e., with group size 1, where one's decisions had no consequences for others), this positive correlation between own decision and expectation can be observed. This comparison suggests that conditionality-perhaps unconsciously-also played a role in these non-conditional treatments.

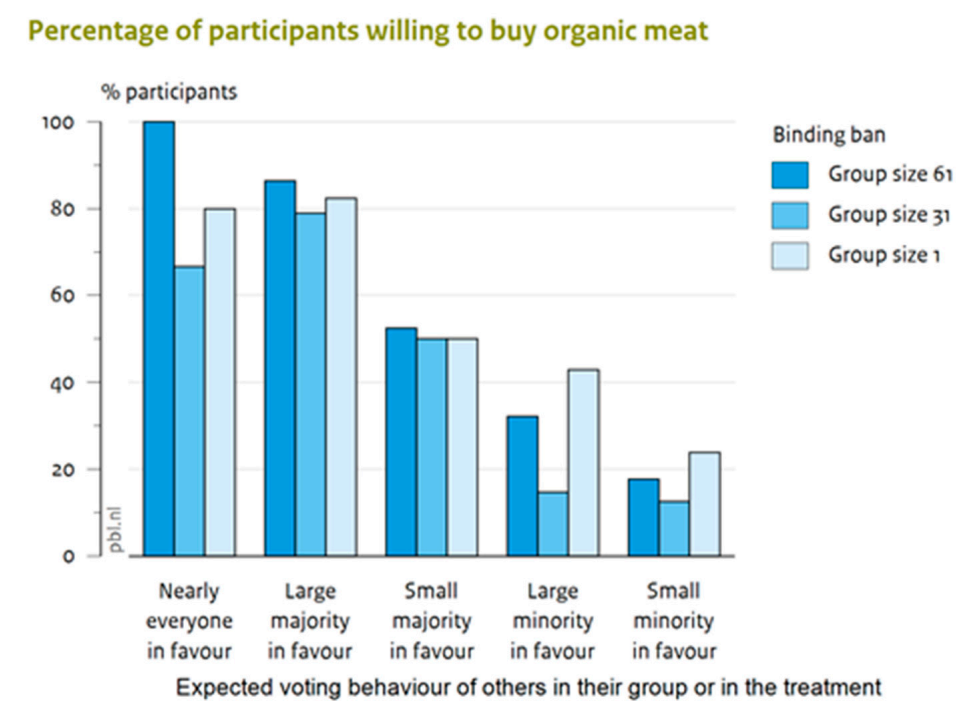

Figure 1. Percentage of participants who voted in favour of the binding agreement to buying only organic meat as a function of their expectations about voting behaviour of others in their group or treatment. 


\subsection{Freedom of Choice Preferred over Restrictive Regulation}

To examine the question what type of policy governments might use we included a non-binding ban and a subsidy treatment, both with group size 31. In the non-binding ban treatment, where participants could only cast an advisory vote, $50 \%$ of the participants voted "Yes" versus $42 \%$ in the binding ban treatment. The difference between these two treatments is not significant ( $p=0.14, \chi^{2}$-test), in contrast to Prediction 3. Thus, it seems that participants were not more prone to yea-saying in the non-binding ban treatment, nor do we observe any evidence that they tried to influence their peers' behaviour (trying to induce them to purchase organic meat, while they themselves spent their budget on conventional meat). Indeed, the participants voted more or less according to their intentions: $55 \%$ of the participants in the non-binding treatment actually spend their budget on organic meat, and all participants who voted in favour of spending the budgets on organic meat effectively did so themselves too even though the vote was non-binding (not for others, but also not for oneself).

In the subsidy treatment, participants could vote as to whether the credit should only be used for compensating the additional costs of organic meat, or whether all group members should be free to spend their budget. As explained in Section 2, the difference between the binding ban and subsidy treatment is primarily a matter of framing, which should not affect behaviour. However, as stated in Prediction 4, if anything we would expect less Yes votes in the subsidy treatment because voting in favour of the subsidy is weakly less financially attractive than voting in favour of the binding ban (if people would spend only part of their budget on purchasing organic meat and the other part on conventional meat; see footnote 9). However, the results show that subsidies are clearly preferred: a significantly higher percentage of participants voted Yes in the subsidy treatment compared to the binding ban treatment (see bottom panel of Table 3,57\% versus $42 \%, \chi^{2}$-test gives $p=0.01$ ). Potential explanations include that participants prefer collective measure that leave the freedom of choice intact (such as subsidies) over restrictive regulations (such as a ban on buying non-organic meat), or that the use of the term subsidy triggers more positive responses. This outcome is consistent with earlier experimental evidence showing that participants who could invest in energy-saving technologies did so more often when the technologies were subsidized, even if this investment (including the subsidy) would be against their own interest from a purely financial perspective [59]. A subsidy may be perceived to be less coercive and less inflicting than a binding ban, and therefore may be supported more.

\subsection{Additional Results from Survey Questions}

Our experimental results imply that individual, moral considerations are more leading in sustainable consumption issues than social dilemma considerations. In this section we present some additional evidence from the post-experimental questionnaire to support our claim.

At the end of the experiment, we invited respondents to fill out a short questionnaire to explain the motivations behind their choices. While the gist of the questions was the same, participants were offered different versions of the survey, depending as to whether they had voted in favour or against the budget being spent on organic meat (see Table 5). If they had voted in favour, we asked whether animal welfare was an important consideration of the decision maker, whether the environment was important, whether the price of meat was unimportant, etc. We asked participants who had voted against the budgets being spent on organic meat more or less the reverse questions-are animal welfare considerations or the environment relatively unimportant in your decision making, is the price of meat important? Both Yes and No voters could choose four options from the list of motives at a maximum. The results of the survey outcomes for the main treatment (binding ban with group size of 31) are shown in Table 5. The outcomes of the other treatments are very similar. For example, in all treatments animal welfare and environment are chosen most frequently by Yes voters, whereas for No voters the price and the averseness to imposing rules on others are most important. Because not all motives are equally valid in all treatments (and the list is not exactly the same for all treatments), the table only shows the results of the main treatment. 
Table 5. Motives for voting in favour of or against the proposition and the percentage of participants who have selected the motive in the main treatment.

\begin{tabular}{|c|c|c|c|}
\hline $\begin{array}{c}\text { Motivations of Participants } \\
\text { Who Voted in Favour of the } \\
\text { Binding Ban }\end{array}$ & $\begin{array}{l}\text { Number of } \\
\text { Participants Who } \\
\text { Agreed with the } \\
\text { Stated Motivation }\end{array}$ & $\begin{array}{l}\text { Motivations of Participants Who } \\
\text { Voted Against of the Binding Ban }\end{array}$ & $\begin{array}{l}\text { Number of } \\
\text { Participants Who } \\
\text { Agreed with the } \\
\text { Stated Motivation }\end{array}$ \\
\hline animal welfare is important to me & 66 & $\begin{array}{l}\text { animal welfare is less important } \\
\text { to me }\end{array}$ & 2 \\
\hline environment is important to me & 43 & $\begin{array}{l}\text { environment is not so important } \\
\text { to me }\end{array}$ & 1 \\
\hline $\begin{array}{l}\text { organic meat is healthier than } \\
\text { non-organic meat }\end{array}$ & 30 & $\begin{array}{l}\text { non-organic meat is healthier than } \\
\text { organic meat }\end{array}$ & 1 \\
\hline $\begin{array}{l}\text { organic meat tastes better than } \\
\text { non-organic meat }\end{array}$ & 28 & $\begin{array}{l}\text { non-organic meat tastes better than } \\
\text { organic meat }\end{array}$ & 4 \\
\hline $\begin{array}{l}\text { I want others to also buy } \\
\text { organic meat }\end{array}$ & 28 & $\begin{array}{l}\text { I do not want to impose on others to } \\
\text { buy organic meat }\end{array}$ & 75 \\
\hline organic meat is readily available & 24 & organic meat is poorly available & 19 \\
\hline other considerations & 24 & other considerations & 8 \\
\hline $\begin{array}{l}\text { I'm not the only one in buying } \\
\text { organic meat }\end{array}$ & 15 & n.a. & - \\
\hline $\begin{array}{l}\text { I think there are plenty of others } \\
\text { will vote for the proposition }\end{array}$ & 13 & $\begin{array}{l}\text { I think too few others will vote for } \\
\text { the proposition }\end{array}$ & 17 \\
\hline $\begin{array}{l}\text { the price of meat is less } \\
\text { important to me }\end{array}$ & 10 & $\begin{array}{l}\text { the price of meat is very } \\
\text { important to me }\end{array}$ & 61 \\
\hline
\end{tabular}

Note: Participants could select up to four motives. Results are for the main treatment (binding ban, group size 31).

The table allows for several interesting observations. First, and not surprisingly, those who voted in favour of spending the budgets on organic meat indicated that animal welfare was an important consideration in their decision process, and so was the environment. Two other motivations standing out in this group are taste and health perceptions. The statement that the price of meat was a not so important consideration was not selected very often by the Yes voters. However, cost considerations were important for those who voted against spending the budgets on organic meat (10 vs. 61). Quite surprisingly, however, is that the latter group essentially did not indicate that animal welfare and the environment were unimportant to them (only 1 of the No voters chose this option). The overriding reason for the No voters to vote against the ban on spending the budgets on conventional meat is their unwillingness to impose rules on others- 75 of the No voters chose this option. This holds for all relevant treatments (this question was not asked in the individual commitment treatment, with group size 1). Thus, even in the advisory treatment, where the voting outcome was not binding, the reluctance to "force" a rule on others was a frequently mentioned motive, which was chosen more often than the other motives, including the price. Finally, although a substantial share of the Yes voters indicated others should also buy organic meat, this motive is clearly less prevalent than animal welfare and environmental considerations.

These survey results suggest that No voters were motivated not only by concerns about the higher individual cost of sustainable products, but also and to a very large extent by their reluctance to impose rules and regulations on others. Participants who said they did not want to impose a rule on others, may have been driven primarily by their dislike of being bound by rules themselves. One may wonder whether this holds for any type of rules or only for specific ones, for example regulations for which they feel responsible. Participants might indeed be in favour of government intervention because they would not have to impose a rule themselves in that case.

To find out to what extent people think that the government should take measures to increase sustainability we also asked participants as to whether the government should impose stricter regulations to improve animal welfare. As part of this question, we explicitly pointed out that such stricter standards would improve the welfare of livestock but would also require significantly 
higher prices. The results (see Table 6) show that about two-thirds of the participants answered that the government should be stricter and that stricter rules were a very good or good idea, while a minority $(7 \%)$ strongly disagreed or disagreed. These results are in line with those of a previous study [33], in which participants were asked the (similarly hypothetical) question as to whether they considered sustainability important, and who should take the lead. Not surprisingly, participants who voted in favour of a binding agreement in our experiment are more supportive of stricter government interventions than No voters. However, even among the latter group, only $10 \%$ of the participants considered stricter government behaviour or regulations a bad or very bad idea while about half were in favour of stricter regulations.

Table 6. Opinions of participants (\%) as to whether the government should impose stricter regulations to improve animal welfare.

\begin{tabular}{lccc}
\hline & \multicolumn{3}{c}{ Voting Behaviour in Experiment } \\
\cline { 2 - 4 } & Against & For & All \\
\hline Should the Government Be More, or Less, Strict? & & & \\
\hline Stricter/Much stricter & 47 & 79 & 64 \\
Neutral & 50 & 21 & 35 \\
Less strict/Much less strict & 2 & 0 & 1 \\
\hline What Would You Think If the Government Imposed Stricter Regulations on Meat Production? ${ }^{\mathbf{b}}$ \\
\hline Good/Very good idea & 50 & 84 & 68 \\
Neutral & 41 & 14 & 26 \\
Bad/Very bad idea & 9 & 3 & 6 \\
\hline
\end{tabular}

a The full question was: "Should the government be more, or less, strict in order to improve animal welfare? Compared to the present situation, the government should be....:" (much stricter, stricter, not more strict or less strict, less strict, much less strict); ${ }^{b}$ The full question was: "If the government decided to impose stricter regulations on meat production, this would have the following consequences: - Animal welfare would be improved; - Meat in the supermarket would become more expensive; - You would be sure that all the meat you buy comes from animal-friendly production systems. What would you think about this? (very good, good, not good not bad, bad, very bad).

A final interesting (and related) finding is on the participants' ex-post satisfaction with the voting outcome of their group (see Table 7). As expected, participants whose group voting outcome turned out to be different from their own votes were less satisfied than participants who decided similarly as their group. This is clear by comparing Columns 1 and 4 in Table 7 on the one hand and Columns 2 and 3 on the other hand. The least satisfied of all participants were those who had voted in favour of a ban on non-organic meat, but whose group decided against it (Column 3 in Table 7). This is somewhat surprising because they at least kept the freedom to buy organic meat, whereas "No voters in Yes groups" (Column 2) lost this freedom of choice. Apparently, it is even more disappointing not to be able to commit yourself and others to buying organic meat, than to be bound by a rule you did not want in the first place. In general, the satisfaction scores are not very sensitive to the treatment.

Table 7. Participants' satisfaction with the voting outcome in their group, conditional on their own vote.* $^{*}$

\begin{tabular}{llllc}
\hline Voting behaviour & $\mathbf{( 1 )}$ & $\mathbf{( 2 )}$ & $\mathbf{( 3 )}$ & $\mathbf{( 4 )}$ \\
\hline Majority vote was & Yes & Yes & No & No \\
Own vote was & Yes & No & Yes & No \\
\hline Satisfaction scores & & & & \\
\hline Binding ban & $5.8^{\mathrm{a}}$ & $4.5^{\mathrm{a}}$ & $3.4^{\mathrm{a}}$ & $5.8^{\mathrm{b}}$ \\
Binding subsidy & $5.8^{\mathrm{b}}$ & $4.3^{\mathrm{b}}$ & - & - \\
\hline
\end{tabular}

* Satisfaction scores ranging from 1 (very dissatisfied) to 7 (very satisfied); a score of 4 means neither satisfied nor dissatisfied. Standard deviations of the means: ${ }^{\mathrm{a}}=0.1,{ }^{\mathrm{b}}=0.2$. No observations because the majority vote in all groups was Yes. 


\subsection{Discussion}

We find that the combination of experimental results and survey outcomes provides little support for the hypothesis that participants view organic meat consumption as a social dilemma. If anything, participants perceive the choice of the type of meat as a decision every household should be free to take. They seem to be caught in a moral dilemma, not only about their individual trade-off in weighing their own (perceived) financial costs and benefits, but also how to take the effects of their decision on others into account, in particular the moral costs of limiting other peoples' room for decision making. As most people are conditionally cooperative as well, participants are significantly more likely to voluntarily commit themselves to purchasing organic meat if (all) others voluntarily do so as well, than to force others (and themselves) to purchasing organic meat by means of voting in favour of a ban on the consumption of conventional meat. Finally, the reluctance to impose rules mainly seems to apply at the level of the individual (i.e., if the individual has to decide), whereas government interventions and regulations are acceptable for a large majority of participants even if those are bans of less sustainable product varieties.

\section{Conclusions}

In this paper, we have explored whether social dilemma considerations play a role in individual decisions regarding sustainability problems-in addition to more personal considerations such as moral concerns. Wicked sustainability problems are hard to experiment with, and therefore we selected a consumption problem that shares some of the key characteristics of the sustainability challenge society faces: meat consumption and animal welfare. We have conducted a large scale (semi-)field experiment with more than 600 participating households, who received budgets to be spent on either organic or conventional meat. An important characteristic of our experiment is that decisions of participants had financial consequences as well as (potential) consequences at home or in the supermarket, not in a lab.

We have implemented several treatments to test whether people tend to view sustainable consumption as a social dilemma-as typically argued by economists—or as a moral dilemma instead. Our experimental results imply that moral considerations are more leading in sustainable consumption issues than social dilemma considerations. The share of households voting in favour of a binding commitment to only buy organic meat does not systematically change if groups are increased from one household (i.e., individual decision making) to 31 households or 61 households. Nevertheless, participants are significantly more likely to voluntarily commit themselves to purchasing organic meat conditional if many others voluntarily do so as well than if they could force others (and themselves) to purchasing organic meat. This finding suggests that social considerations are not completely absent. Finally, support for subsidies on the consumption of organic meat is larger than the support for the ban on conventional meat, even though the former is financially less attractive. Survey responses indicate that many people are reluctant to restrict the choice set of one's peers, but at the same time also suggest substantial support for the government to regulate unsustainable product varieties. The insights obtained have potentially important consequences for policies aimed at fostering sustainable consumption. Consumers are not opposed to government interventions, albeit that moral considerations are more important for the support for government intervention than social dilemma considerations. In addition, less restrictive policies (such as subsidies) seem to receive larger support than more restrictive ones (such as bans). However, because of the moral dimension, even less invasive instruments—such as nudges [60]—-may be very effective too.

Of course, our study has several limitations and the results cannot be translated one-on-one to all sustainability issues we currently face (such as climate change and biodiversity conservation), even though the decision-making process and purchases happened to take place in the participants' natural environments. For instance, the duration and scope of the experiment were limited to one week's meat consumption. Hence, we cannot say much about the implications for a longer period of time or other products. In addition, the support in favour of the sustainable choice would probably be lower if the experiment lasted longer or would have been repeated. Therefore, we might consider our 
findings as an upper bound for people's longer-term preferences. On the other hand, and in contrast to more traditional techniques such as surveys and contingent valuation studies, the decisions taken by participants in our experiment had real financial consequences, and hence our experiment is likely to have captured their real preferences.

Acknowledgments: We thank Zach Brown, Nick Johnstone and the participants of the SABE/IAREP Conference (Wageningen University, 8-10 July, 2016) and of the NCBEE (BI Norwegian Business School, 30 September1 October, 2016), and two anonymous reviewers for their very useful comments and suggestions on an earlier version of this paper. The authors gratefully acknowledge financial support by the Netherlands Environmental Assessment Agency (PBL) and the OECD for financial support, and Daan van Soest also thanks the European Commission for funding via the Seventh Framework Program (FP7/2007-2013), grant agreement No. 613420 (Glamurs). All remaining errors are ours.

Author Contributions: All authors were involved in all phases of the project-design, implementation, analysis, interpretation and the write-up of the manuscript.

Conflicts of Interest: The authors declare no conflict of interest.

\section{Appendix A. Setup and instructions of the 'binding ban' treatment-the main treatment.}

This appendix describes in detail the treatment in which participants had to vote on banning the purchase of non-organic meat. The instructions for the other treatments are similar (and available upon request). In this treatment, the majority vote was binding: in the week following the poll, participants had to buy meat in compliance with their group's decision (only organic meat; or whichever they preferred: organic or non-organic). Before the vote, participants were provided with the following information on organic meat:

Organic meat comes from animals that have had a better life than animals raised in intensive livestock systems (also known as bio-industry or factory farming). Pigs can go outside and root in the mud. Chickens can scratch around. Cows graze in the fields for the greater part of the year. The animal houses have windows, fresh air coming in, and straw bedding. Independent scientific research by Wageningen University has shown that animal welfare on organic farms is higher (animals are less stressed, less anxious, etc.) than on conventional factory farms.

Nowadays organic meat can be bought in most supermarkets. If more people buy organic meat, livestock production in the Netherlands will become more animal-friendly.

However, organic meat is on average about twice as expensive as conventional (non-organic) meat.

At present, the vast majority of Dutch households buy non-organic meat. As a result, animal welfare is hardly improving. If more people switch to buying organic meat, more animals will get a better life.

Next, participants were divided into groups of 31 each. This group size was deemed sufficient for a convincing gain in animal welfare if all group members were to buy organic meat, compared to the effect of just one participant buying organic meat. Before the vote took place, all participants were informed that a certain amount of money had been reserved for each of them, as a kind of shopping credit. This credit roughly covered the additional expenses of buying organic meat instead of non-organic meat, for one week, for one household. These additional costs were estimated at 7 euros for an adult and 4 euros for a child. Daily meat consumption was assumed to be $120 \mathrm{~g}$ for adults and $70 \mathrm{~g}$ for children. Each participant was informed how much credit was reserved for him or her, based on the size and composition of their household. The remainder of this example is based on a two-adult household, with a credit of $2 \times 7=14$ Euros.

Next, the participants were shown the proposition to vote on:

All households shall use their credit only for buying organic meat.

Before the participants could vote on this proposition, the pros and cons of buying organic meat were explained in more detail:

If all 31 households would use their credit for buying organic meat, this would have a greater impact than if only one household would buy organic meat. 
If 1 household switches to buying organic chicken breast, then each week 1 chicken will have a better life. If all 31 households switch to buying organic chicken breast, then each week 40 chickens will have a better life.

However, organic meat is on average about twice as expensive as non-organic meat. The table below shows, for three kinds of meat, how much meat you can buy with an average week budget for a household of your size.

Amount of meat that can be bought with 14 euros.

$\begin{array}{lll} & \text { Non-organic } & \text { Organic } \\ \text { Minced beef } & 2.9 \text { kilos } & 1.3 \text { kilos } \\ \text { Shoulder chop } & 2.5 \text { kilos } & 1.3 \text { kilos } \\ \text { Chicken breast } & 1.8 \text { kilos } & 0.6 \text { kilos }\end{array}$

In the actual poll, the weights in this table were adjusted to the size and composition of the household of the participant in question. This example table is based on a two-adult household. Next, all participants were invited to cast their vote:

You are now invited to cast your vote on the following proposition:

"All 31 households shall use their credit only for buying organic meat."

I vote IN FAVOUR (I think that all 31 households should use their credit only for buying organic meat).

I vote AGAINST (I think that all 31 households should be free to use their credit for buying organic or non-organic meat).

After everyone had cast their vote, we calculated the results and informed the participants of the voting outcome in their group. The majority decision was binding. Thus, if the majority of the group was of the opinion that the credit should be used only for buying organic meat, then the credit could be spent only on organic meat. In that case, participants were reimbursed only for their purchases of organic meat, up to their credit limit. If the majority had voted against the proposition, then participants could decide for themselves whether to buy organic or non-organic meat. In that case they were reimbursed for all their meat purchases, up to their credit limit. We checked the receipts to ensure that participants had made their purchases in compliance with their group's decision. In the case that participants were free to choose between organic and non-organic meat, the receipts allowed us to track their purchasing choices (Note: Although a binding vote is the most accurate method to measure preferences, it may obscure the relation between preferences and ex post behaviour. If the majority is in favour of spending the credit only on organic meat and the vote is binding, then some members of the group will have to buy organic meat while they voted against it. As long as they value animal welfare to some degree, they are better off buying organic meat. Moreover, they might as well buy organic meat because the additional costs are covered by their credit: their expenses are the same whether they buy organic or non-organic meat. Only when the majority is against using the credit only for organic meat, we can gain insight into the relation between preferences and purchasing behaviour; in that case, participants are free to choose whether to buy organic or non-organic meat, based on their own preferences. As it happened very rarely that the group majority was against the statement, the number of observations is too low to allow for a proper analysis).

In this 'binding ban' poll, all participants had to comply with the majority decision, and therefore the optimum strategy for each individual was to vote truthfully: the poll question was incentive compatible' $[35,56]$. For the individual participant, the probability of his/her vote being decisive is small. However, in the case that there are already 15 votes in favour and 15 votes against the proposition, the 31st voter who votes a socially desirable 'yes' despite feeling that that the collective benefits are smaller than the individual costs, will afterwards regret his or her untruthful vote. As none of the participants will know beforehand whether their vote will be the decisive one or not, the safest strategy is to vote truthfully. 


\section{References}

1. Stern, N. The Economics of Climate Change; Cabinet Office, HM Treasury: London, UK, 2007.

2. Fornara, F.; Pattitoni, P.; Mura, M.; Strazzera, E. Predicting intention to improve household energy efficiency: The role of value-belief-norm theory, normative and informational influence, and specific attitude. J. Environ. Psychol. 2016, 45, 1-10. [CrossRef]

3. Belanche, D.; Casaló, L.V.; Flavián, C. Understanding the cognitive, affective and evaluative components of social urban identity: Determinants, measurement, and practical consequences. J. Environ. Psychol. 2007, 50, 138-153. [CrossRef]

4. Dholakia, U.M.; Bagozzi, R.P.; Pearo, L.K. A social influence model of consumer participation in network-and small-group-based virtual communities. Int. J. Res. Market. 2004, 21, 241-263. [CrossRef]

5. Olsen, M.C. The Logic of Collective Action: Public Goods and the Theory of Groups; Harvard University Press: Cambridge, MA, USA, 1965.

6. Ostrom, E. Collective action and the evolution of social norms. J. Econ. Perspect. 2000, 14, 137-158. [CrossRef]

7. Vringer, K.; Aalbers, T.G.; Blok, K. Household energy requirement and value patterns. Energy Policy 2007, 25, 553-566. [CrossRef]

8. Kirchgässner, G. On minimal morals. Eur. J. Political Econ. 2010, 26, 330-339. [CrossRef]

9. Ledyard, J. Public Goods: A Survey of Experimental Research. Chapter 2. In Handbook of Experimental Economics; Kagel, J., Roth, A., Eds.; Princeton University Press: Princeton, NJ, USA, 1995; pp. 111-194.

10. Food and Agriculture Organization of the United Nations (FAO). SAFA: Sustainability Assessment of Food and Agriculture System. Guideline Version 3.0.; FAO: Rome, Italy, 2014.

11. Schader, C.; Stolze, M.; Niggli, U. How the organic food system contributes to sustainability. In Assessing Sustainable Diets within the Sustainability of Food Systems Proceedings of the International Workshop, CREA, Rome, Italy, 15-16 September 2014; Food and Agriculture Organization of the United Nations (FAO): Rome, Italy, 2015; pp. 27-36.

12. Gattinger, A.; Muller, A.; Haeni, M.; Skinner, C.; Fliessbach, A.; Buchmann, N.; Mäder, P.; Stolze, M.; Smith, P.; Scialabba, N.E.-H. Enhanced top soil carbon stocks under organic farming. Proc. Natl. Acad. Sci. USA 2012, 109, 18226-18231. [CrossRef] [PubMed]

13. Tuomisto, H.; Hodge, I.; Riordan, P.; Macdonald, D. Does organic farming reduce environmental impacts? A meta-analysis of European research. J. Environ. Manag. 2012, 112, 309-320. [CrossRef] [PubMed]

14. Netherlands Environmental Assessment Agency (PBL). De Macht van het Menu. Opgaven en Kansen Voor Duurzaam en Gezond Voedsel; (The Power of the Menu. Challenges and Opportunities for Sustainable and Healthy Food); PBL: The Hague, The Netherlands, 2013.

15. Meier, M.S.; Stoessel, F.; Jungbluth, N.; Juraske, R.; Schader, C.; Stolze, M. Environmental impacts of organic and conventional agricultural products—are the differences captured by life cycle assessment? J. Environ. Manag. 2015, 149, 193-208. [CrossRef] [PubMed]

16. Belk, R.W. Materialism: Trait aspects of living in the material world. J. Consum. Res. 1985, 12, $265-280$. [CrossRef]

17. Borgmann, A. The moral complexion of consumption. J. Consum. Res. 2000, 26, 418-422. [CrossRef]

18. Cohen, J.; Darian, J. Disposable products and the environment: A consumer behavior perspective. Res. Consum. Behav. 2000, 9, 227-259.

19. Moisander, J. Motivational complexity of green consumerism. Int. J. Consum. Stud. 2007, 31, 404-409. [CrossRef]

20. Sheth, J.N.; Sethia, N.K.; Srinivas, S.J. Mindful consumption: A customer-centric approach to sustainability. J. Acad. Mark. Sci. 2011, 39, 21-39. [CrossRef]

21. Kurz, T. The psychology of environmentally sustainable behavior: Fitting together pieces of the puzzle. Anal. Soc. Issues Public Policy 2002, 2, 257-278. [CrossRef]

22. Gupta, S.; Ogden, D.T. To buy or not to buy? A social dilemma perspective on green buying. J. Consum. Mark. 2009, 26, 376-391. [CrossRef]

23. Tanner, C.; Wölfing Kast, S. Promoting Sustainable Consumption: Determinants of Green Purchases by Swiss Consumers. Psychol. Mark. 2003, 20, 883-902. [CrossRef]

24. Young, W.; Hwang, K.; McDonald, S.; Oates, C.J. Sustainable consumption: Green consumer behaviour when purchasing products. Sustain. Dev. 2010, 18, 20-31. [CrossRef] 
25. Willer, H. The European Market for Organic Food; Forschungsinstitut für Biologischen Landbau (FiBL): Frick, Switzerland, 2012.

26. Bionext. Bionext Trendrapport 2015-June 2016, Ontwikkeling Biologische Landbouw en Voeding Nederland. In Bionext trendreport 2015-June 2016, Development Sustainable Food the Netherlands; Bionext: Zeist, The Netherlands, 2016.

27. Biomonitor; Monitor Duurzaam Voedsel. Task Force Marktontwikkeling Biologische Landbouw Biologica. In Biomonitor 2012, Monitor Sustainable Food (2012) Task Force Market Development Organic Agriculture, Biological; Minsterie van Economische Zaken: The Hague, The Netherlands, 2013.

28. Max Havelaar. Jaarverslag 2010 Stichting Max Havelaar; Annual Report; Max Havelaar Foundation: Utrecht, The Netherlands, 2010.

29. Visser, H.; Aalbers, T.G.; Vringer, K.; Verhue, D. How Dutch Citizens Prioritise the Social Agenda; An Analysis of the 2003, 2005 and 2006 Surveys; Report 500086002; Netherlands Environmental Assessment Agency: Bilthoven, The Netherlands, 2007.

30. Verbeek, D.; Boelhouwer, J. Milieu van Later, Wiens Zorg Nu? In Wisseling van de Wacht: Generaties in Nederland. Sociaal en Cultureel Rapport; van den Broek, A., Bronneman-Helmers, R., Veldheer, V., Eds.; SCP, The Hague. Chapter in report of the Netherlands Institute for Social Research SCP: The Hague, The Netherlands, 2010.

31. Schelling, T.C. Micromotives and Macrobehavior; W.W. Norton \& Company: New York, NY, USA, 1978.

32. Sen, A. Choice, Orderings and Morality. In Practical Reason; Körner, S., Ed.; Blackwell: Oxford, UK, 1974; pp. 54-67.

33. MNP. Nederland en een Duurzame Wereld. Armoede, Klimaat en Biodiversiteit. Tweede Duurzaamheidsverkenning; (The Netherlands in a Sustainable World. Poverty, Climate and Biodiversity: Second Sustainability Outlook); Netherlands Environmental Assessment Agency MNP: Bilthoven, The Netherlands, 2007.

34. Middelkoop, M.; Vringer, K.; Visser, H. Are Dutch residents ready for a more stringent policy to enhance the energy performance of their homes? Energy Policy 2017, 105, 269-282. [CrossRef]

35. Carson, R.; Groves, T. Incentive and informational properties of preference questions. Environ. Resour. Econ. 2007, 37, 181-210. [CrossRef]

36. List, J.A.; Gallet, C.A. What Experimental Protocol Influence Disparities between Actual and Hypothetical Stated Values? Environ. Resour. Econo. 2001, 20, 241-254. [CrossRef]

37. Murphy, J.P.; Allen, P.G.; Stevens, T.H.; Weatherhead, D. A Meta-analysis of Hypothetical Bias in Stated Preference Valuation. Environ. Resour. Econ. 2005, 30, 313-325. [CrossRef]

38. Harrison, G.W. Experimental evidence on alternative environmental valuation methods. Environ. Resour. Econ. 2006, 34, 125-162. [CrossRef]

39. Harrison, G.W.; Rutström, E.E. Chaper 81. Experimental Evidence on the Existence of Hypothetical Bias in Value Elicitation Methods. In Handbook of Experimental Economics Results; Plott, C., Smith, V.L., Eds.; Elsevier Science: New York, NY, USA, 2008; pp. 752-767.

40. De Graaf, S.; Vanhonacker, F.; Van Loo, E.; Lauwers, J.L.; Tuyttens, F.; Verbeke, W. Market opportunities for animal-friendly milk in different consumer segments. Sustainability 2016, 8, 1302. [CrossRef]

41. Dagevos, H.; Sterrenberg, L. Burgers en Consumenten: Tussen Tweedeling en Twee-Eenheid; Wageningen Pers: Wageningen, The Netherlands, 2003.

42. Harrison, G.W.; List, J.A. Field experiments. J. Econ. Lit. 2004, 42, 1013-1059. [CrossRef]

43. Levitt, S.D.; List, J.A. What do laboratory experiments measuring social preferences reveal about the real world? J. Econ. Perspect. 2007, 21, 153-174. [CrossRef]

44. Vringer, K.; Vollebergh, H.; van Soest, D.; van der Heijden, E.; Dietz, F. Dilemma's Rond Duurzame Consumptie: Een Onderzoek Naar Het Draagvlak Voor Verduurzaming van Consumptie; (Dilemmas Surrounding Sustainable Consumption: A Study on Consumer Support for Increasing the Sustainability of Consumption); Netherlands Environmental Assessment Agency PBL: The Hague, The Netherlands, 2013.

45. Gilsing, A.M.; Weijenberg, M.P.; Goldbohm, R.A.; Dagnelie, P.C.; van den Brandt, P.A.; Schouten, L.J. The Netherlands Cohort Study-Meat Investigation Cohort; a population-based cohort over-represented with vegetarians, pescetarians and low meat consumers. Nutr. J. 2013, 12, 156. [CrossRef] [PubMed]

46. Dagevos, H.; Voordouw, J. Sustainability and meat consumption: Is reduction realistic? Sustainability 2013, 9 , 60-69. 
47. Brandt, K. Organic Agriculture and Food Utilisation. In Proceedings of the International Conference on Organic Agriculture and Food Security, Rome, Italy, 3-5 May 2007.

48. Olsson, V.; Andersson, K.; Hansson, I.; Lundström, K. Differences in meat quality between organically and conventionally produced pigs. Meat Sci. 2003, 64, 287-297. [CrossRef]

49. Wal, P.G.; van der Mateman, G.; de Vries, A.W.; Vonder, G.M.A.; Smulders, F.J.M.; Geesink, G.H.; Engel, B. 'Scharrel' (free range) pigs: Carcass composition, meat quality and taste-panel studies. Meat Sci. 1993, 34, 27-37. [PubMed]

50. Andreoni, J. Impure Altruism and Donations to Public Goods: A Theory of Warm-Glow Giving. Econ. J. 1990, 100, 464-477. [CrossRef]

51. Kahneman, D.; Knetsch, J. Valuing public goods: The purchase of moral satisfaction. J. Environ. Econom. Manag. 1992, 22, 57-70. [CrossRef]

52. Ariely, D.; Loewenstein, G.; Prelec, D. 'Coherent Arbitrariness': Stable Demand Curves without Stable Preferences. Q. J. Econ. 2003, 118, 73-105. [CrossRef]

53. Bateman, I.J.; Burgess, D.; Hutchinson, W.G.; Matthews, D.I. Learning Design Contingent Valuation (LDCV): NOAA Guidelines, Preference Learning and Coherent Arbitrariness. J. Environ. Econ. Manag. 2008, 55, 127-141. [CrossRef]

54. Diamond, P.A.; Hausman, J.A. Contingent Valuation: Is Some Number Better than No Number? J. Econ. Perspect. 1994, 8, 45-64. [CrossRef]

55. Hanemann, W.M. Valuing the Environment through Contingent Valuation. J. Econ. Perspect. 1994, 8, $19-43$. [CrossRef]

56. Cummings, R.G.; Harrison, G.W.; Rutström, E.E. Homegrown values and hypothetical surveys: Is the dichotomous choice approach incentive-compatible? Am. Econom. Rev. 1995, 85, 260-266.

57. Selten, R. Die Strategiemethode zur Erforschung des Eingeschränkt Rationalen Verhaltens im Rahmen Eines Oligopolexperiments. In Beiträge zur Experimentellen Wirtschaftsforschung; Sauermann, H., Ed.; Mohr: Tübingen, Germany, 1967; pp. 136-168.

58. Fischbacher, U.; Gächter, S.; Fehr, E. Are people conditionally cooperative? Evidence from a public goods experiment. Econ. Lett. 2001, 71, 397-404. [CrossRef]

59. Aalbers, R.F.T.; van der Heijden, E.C.M.; Potters, J.J.M.; van Soest, D.P.; Vollebergh, H.R.J. Technology adoption subsidies: An experiment with managers. Energy Econ. 2009, 31, 431-442. [CrossRef]

60. Thaler, R.; Sunstein, C.R. Nudge: Improving Decisions about Health, Wealth, and Happiness; Yale University Press: New Haven, CT, USA, 2008. 